\title{
Supervised versus unsupervised antimalarial treatment with six-dose artemether-lumefantrine: pharmacokinetic and dosage-related findings from a clinical trial in Uganda
} Francesco Checchi*1,2, Patrice Piola1, Carole Fogg ${ }^{1}$, Francis Bajunirwe ${ }^{3}$, Samuel Biraro1, Francesco Grandesso' ${ }^{1}$, Eugene Ruzagira1, Joseph Babigumira ${ }^{1}$, Isaac Kigozi ${ }^{1}$, James Kiguli ${ }^{3}$, Juliet Kyomuhendo ${ }^{1}$, Laurent Ferradini ${ }^{1}$, Walter RJ Taylor ${ }^{4}$ and Jean-Paul Guthmann ${ }^{1}$

Address: ${ }^{1}$ Epicentre, Paris, France, ${ }^{2}$ Department of Infectious and Tropical Diseases, London School of Hygiene and Tropical Medicine, London, UK, ${ }^{3}$ Mbarara University of Science and Technology, Mbarara, Uganda and ${ }^{4}$ UNICEF/UNDP/World Bank/WHO Special Programme for Research and Training in Tropical Diseases, Geneva, Switzerland

Email: Francesco Checchi* - francesco.checchi@lshtm.ac.uk; Patrice Piola - uganda@epicentre.msf.org; Carole Fogg - carolefogg@yahoo.co.uk; Francis Bajunirwe - francis.bajunirwe@cwru.edu; Samuel Biraro - birarosj@yahoo.co.uk;

Francesco Grandesso - francesco.grandesso@epicentre.msf.org; Eugene Ruzagira - eruzagira@yahoo.com;

Joseph Babigumira - babijo@ hotmail.com; Isaac Kigozi - kigoziisaac76@yahoo.co.uk; James Kiguli - mbararalab@yahoo.fr;

Juliet Kyomuhendo - julietkyomuhendo@yahoo.com; Laurent Ferradini - msffr.comed@online.com.kh; Walter RJ Taylor - taylorw@who.int;

Jean-Paul Guthmann - jean-paul.guthmann@epicentre.msf.org

* Corresponding author

Published: 19 July 2006

Malaria Journal 2006, 5:59 doi:10.1 186/1475-2875-5-59

This article is available from: http://www.malariajournal.com/content/5/I/59

(C) 2006 Checchi et al; licensee BioMed Central Ltd.

This is an Open Access article distributed under the terms of the Creative Commons Attribution License (http://creativecommons.org/licenses/by/2.0), which permits unrestricted use, distribution, and reproduction in any medium, provided the original work is properly cited.
Received: 22 May 2006

Accepted: 19 July 2006

\begin{abstract}
Background: A six-dose antimalarial regimen of artemether-lumefantrine (A/L) may soon become one of the most widely used drug combination in Africa, despite possible constraints with adherence and poor absorption due to inadequate nutrition, and a lack of pharmacokinetic and effectiveness data.

Methods: Within a trial of supervised versus unsupervised A/L treatment in a stable Ugandan Plasmodium falciparum transmission setting, plasma lumefantrine concentrations were measured in a subset of patients on day $3\left(\mathrm{C}[\mathrm{lum}]_{\mathrm{day} 3}\right)$ and day $7\left(\mathrm{C}[\mathrm{lum}]_{\mathrm{day} 7}\right)$ post-inclusion. Predictors of lumefantrine concentrations were analysed to show how both $C[\text { lum }]_{\text {day } 7}$ and the weight-adjusted lumefantrine dose affect 28-day recrudescence and re-infection risks. The implications of these novel findings are discussed in terms of the emergence of lumefantrine-resistant strains in Africa.

Results: C [lum $]_{\text {day } 3}$ and C [lum $]_{\text {day } 7}$ distributions among 24 I supervised and 238 unsupervised patients were positively skewed. Unsupervised treatment and decreasing weight-adjusted lumefantrine dose were negatively associated with $C[\mathrm{lum}]_{\text {day } 3}$. Unsupervised treatment and decreasing age showed strong negative associations with $C[\mathrm{lum}]_{\mathrm{day} 7}$. Both models were poorly predictive (R-squared $<0.25$ ). There were no recrudescences in either arm, but decreasing lumefantrine dose per $\mathrm{Kg}$ resulted in up to I3-fold higher adjusted risks of re-infection. Re-infections occurred only among patients with $C$ [lum] day7 below $400 \mathrm{ng} /$ $\mathrm{mL}(\mathrm{p}<0.00 \mathrm{I})$.
\end{abstract}

Conclusion: Maintaining the present six-dose regimen and ensuring high adherence and intake are essential to maximize the public health benefits of this valuable drug combination. 


\section{Background}

The fixed dose antimalarial combination of artemetherlumefantrine $(\mathrm{A} / \mathrm{L})$ is a promising and efficacious artemisinin-based combination treatment (ACT) that could play a key role in reducing the high mortality suffered by African children with Plasmodium falciparum malaria. The three day, six dose regimen of $\mathrm{A} / \mathrm{L}$ is currently prioritized by the World Health Organization as a replacement for failing antimalarial monotherapies, notably chloroquine and sulfadoxine-pyrimethamine (SP). Several countries (e.g. Zambia, Kenya, Tanzania, South Africa, Niger, and Uganda) have now adopted $\mathrm{A} / \mathrm{L}$ as the first line antimalarial. Clinical trials have shown A/L to be safe and highly efficacious [1]. However, in routine practice, several drawbacks may reduce its effectiveness. Absorption of the longer-acting, lipophilic partner drug, lumefantrine, is highly dependent on the intake of food, especially lipids. Its oral bioavailability varied sixteen-fold in fasting healthy Thai volunteers compared to volunteers who had taken a fatty meal. Taking a light (500 calories, $10 \mathrm{~g}$ fat) or 'normal' (1,000 calories, $20 \mathrm{~g}$ fat) meal within one hour either side of the first $\mathrm{A} / \mathrm{L}$ dose increased lumefantrine bioavailability by a mean factor of $48 \%$ and $108 \%$, respectively, compared to fluids alone[2]. In these volunteers, the relative bioavailability increased three-fold with the third and fourth doses compared to the first two doses because appetite improved rapidly in parallel with clinical recovery. There is also considerable inter-individual variation in the peak plasma lumefantrine concentration $\left(\mathrm{C}_{\max }\right)$ in volunteers and in patients [2]. In Thai patients, the lower and upper fifth percentile $\mathrm{C}_{\max }$ of the three day, six dose regimen were 1,100 and $19,800 \mathrm{ng} / \mathrm{mL}$ respectively, an eighteen-fold difference [3].

The spacing of each dose is also important according to the manufacturer (Novartis Pharma, Basel, Switzerland). The first and second doses should be taken eight hours apart. The remaining doses (two doses on the subsequent two days) should be taken 12 hours apart with the third dose taken 24 hours after the first. To help with this complex regimen, A/L is currently packaged in an illustrated, patient-friendly blister. Assessment of this packaging in Mbarara, Uganda resulted in high rates of adherence and a day 3 median (range) lumefantrine concentration in patients of all ages of 2,450 (600 to 11,400$) \mathrm{ng} / \mathrm{mL}$ [4]. The median concentration in children under five, however, was significantly lower than in older children and adults [4].

Outside the research setting, poor adherence might compound the problems of poor lipid intake and dose spacing, and further contribute to sub-optimal lumefantrine blood concentrations. Dose ranging studies have established that the key pharmacokinetic (PK) determinant of cure for $\mathrm{A} / \mathrm{L}$ is the area under the concentration time curve
(AUC) of the longer acting lumefantrine, and, therefore, the time during which lumefantrine concentrations exceed both the minimum parasiticidal (MPC) and minimum inhibitory (MIC) concentrations of the parasites. In multi-drug resistant areas of Thailand, the day 7 lumefantrine concentration was a useful surrogate for AUC. A concentration of less than $280 \mathrm{ng} / \mathrm{ml}$ was a useful predictor of treatment failure and may approach the in vivo MIC of parasites from this area $[2,3]$. Factors leading to a lowering of the AUC will reduce the probability of cure and could shorten the therapeutic lifespan of $\mathrm{A} / \mathrm{L}$, by exposing parasites to sub-therapeutic lumefantrine concentrations, thus favouring the emergence of lumefantrine-resistant strains.

Pharmacokinetic studies of lumefantrine have been conducted in Chinese, Thai and European adult patients and in a very small number of children between 6 and 12 years of age $[2,3,5-7]$, but published data from sub-Saharan Africa, where the drug is most likely to see widespread use, are lacking. In particular, young children under five are conspicuously absent from the literature. Our group previously reported a trial of supervised versus unsupervised A/L for treatment of uncomplicated falciparum malaria in Ugandan patients of all ages. Both methods of treatment administration were highly effective, achieving cure rates exceeding 95\% [8]. Here, lumefantrine pharmacokinetic findings from a subset of these patients are presented, and their determinants and effects on novel infections during 28 days of follow up are examined.

\section{Methods \\ Study procedures}

Trial methods are detailed elsewhere [8]. Briefly, the study was conducted in Mbarara, southwestern Uganda, an area of multi-drug resistant $P$. falciparum $[9,10]$. Ethical approval was obtained from Mbarara University of Science and Technology and from the Uganda National Council for Science and Technology. After obtaining written informed consent, non-pregnant, uncomplicated malaria patients with symptomatic $P$. falciparum monoinfection (500 to $100,000 / \mu \mathrm{L}$ ) were randomized to a six dose regimen of either supervised or unsupervised A/L (Novartis Pharma, Basel, Switzerland), according to body weight: (i) one tablet (artemether $20 \mathrm{mg} /$ lumefantrine $120 \mathrm{mg}$ ) per dose (10-14.9 Kg), (ii) two tablets/dose (15$24.9 \mathrm{Kg}$ ), (iii) three tablets/dose (25-34.9 Kg), and (iv) four tablets/dose $(\geq 35 \mathrm{Kg}$ ). In the supervised arm, each dose administration was directly observed for 30 minutes, and the whole dose was repeated in case of vomiting. 300 mL milk ( $\sim 10 \mathrm{~g}$ fat) and 30 g groundnuts ( $13 \mathrm{~g}$ fat) were given with each supervised dose. For small children, the tablet was dissolved in water and spoon-fed, and the fat source consisted of breast milk. Doses one and two were given exactly eight hours apart, dose three was given at 8 a.m. the following morning (about 24 hrs after dose one), 
and the remaining doses 12 hours apart. Unsupervised patients received the first dose as above, but were given the remainder of the blister pack for home administration, along with a standardized message on dose spacing and appropriate food intake.

Patients were assessed on days 3, 7, 14, 21 and 28 for safety and efficacy endpoints. Recurrent parasitaemias between days 7 and 28 were analysed by a polymerase chain reaction (PCR) comparing the pre- and post-treatment genotypes of the parasite loci coding for the merozoite surface proteins 1 and 2 (MSP-1 and MSP-2) and the glutamate rich protein (GLURP)[11], so as to distinguish new from recrudescent infections. Parasitological failure was defined as any occurrence of PCR-confirmed recrudescent parasitaemia during follow-up (irrespective of symptoms).

Sampling in the trial was stratified to compare cure rates in three age groups: under 5 years, 5-14 years, and 15 and above. In each arm and age group, 70 patients per group were randomly sampled for plasma lumefantrine levels on days 3 and 7 (i.e. 210 supervised and 210 unsupervised). These patients were selected using simple random sampling from the treatment allocation lists. Venous blood $(4 \mathrm{~mL})$ was collected in heparinized vacutainers during the days 3 and 7 morning visits. Blood samples were immediately centrifuged and plasma stored in cryotubes at $-70^{\circ} \mathrm{C}$ up to and including transport to Novartis Pharma in Paris, France, where plasma lumefantrine levels were determined blindly using a previously described high performance liquid chromatography (HPLC) method. This method detects $\mathrm{C}$ [lum] values $>5 \mathrm{ng} / \mathrm{mL}$, with coefficients of variation of 1.8 to $4.2 \%$ [12].

\section{Statistical analysis}

Data were double-entered on EpiData 3.0 (the Epidata Association, Odense, Denmark), and analysed using Stata 8.2 (Stata Corp., College Station, Texas, USA). Lumefantrine concentrations were compared by arm within age groups using the unpaired t-test, and $\mathrm{C}[\mathrm{lum}]_{\mathrm{day} 3}$ and $\mathrm{C}$ [lum $]_{\text {day } 7}$ were correlated using Spearman's rho correlation coefficients. The association between baseline patient variables and $\mathrm{C}[\mathrm{lum}]_{\mathrm{day} 3}$ or $\mathrm{C}[\mathrm{lum}]_{\mathrm{day} 7}$ was then analysed in separate multivariate linear regression models, proceeding as follows. First, the dependent variable (lumefantrine concentration) was transformed into its square $\operatorname{root}\left(\mathrm{C}[\mathrm{lum}]_{\text {day3 }}\right)$ or natural logarithm (C [lum $\left.]_{\text {day } 7}\right)$ so as to normalize distributions. For each patient, the weightadjusted lumefantrine dose prescribed in $\mathrm{mg} / \mathrm{Kg}$ was then calculated ( $=$ number of tablets per dose $\times 6$ doses $\times 120$ $\mathrm{mg} /$ dose/bodyweight in $\mathrm{Kg}$ ), and categorized as $<50,50-$ $64,65-79$, and $\geq 80 \mathrm{mg} / \mathrm{Kg}$, which corresponded almost exactly to $1 \mathrm{SD}$ intervals away from the mean of $64 \mathrm{mg} / \mathrm{Kg}$. Certain baseline parameters were selected as independent explanatory variables for inclusion in the models: (i) if they appeared likely to represent plausible biological or epidemiological predictors (referral from hospital outpatient department vs. outlying clinics; gender; history of anorexia, nausea, vomiting, abdominal pain, diarrhoea, or fatigue; hepatomegaly; day 0 axillary temperature; asexual parasite density; haemoglobin; presence of concomitant febrile illness; and co-administration of antibiotics or antihelminthics); or (ii) if they were associated with the outcome at the $\mathrm{p}<0.20$ level in a univariate analysis (history of dizziness, gametocytaemia). The regression was performed on all selected explanatory variables, and nonsignificant ones were then progressively removed. Dropped variables were then re-added one by one and retained if they affected the model or were associated significantly with the outcome. Weight-adjusted lumefantrine dose, age group and arm were forced into all final models (this was done since the association of these variables with the outcome seemed very biologically plausible; however, alternative models were also constructed without forcing these variables). After searching for plausible interactions and assessing the effect of influential data points, model assumptions were tested, including normality of residuals, linearity between dependent and explanatory variables, lack of collinearity among explanatory variables, and constant variance (homoscedasticity).

The association between the weight-adjusted lumefantrine dose and the risk of re-infection during the 28 days of follow-up was then analysed by the Cox proportional hazards model, controlling for potential confounders. All enrolled patients who were analysable by intention to treat (ITT) were included in this analysis [8]. Among baseline explanatory variables considered potential confounders (hospital attendance, gender, day 0 axillary temperature, splenomegaly, asexual density, gametocytaemia, and haemoglobin), those with a $\mathrm{p}<0.20$ in the univariate analysis of the outcome (re-infection) were selected. The final model was constructed manually as described above. After searching for interactions, the proportional hazards assumption that relative risks do not vary with time was tested.

Finally, the Log-Rank test was used to compare the probability of survival (i.e. of remaining re-infection free) from day 7 as a function of the C [lum $]_{\text {day } 7}$ levels: $<200,200-$ $399,400-599$, and $\geq 600 \mathrm{ng} / \mathrm{mL}$.

\section{Results}

\section{Pharmacokinetics}

Baseline characteristics of the 479 patients who had at least one pharmacokinetic sampling are shown in Table 1. No $C$ [lum $]_{\mathrm{day} 3}$ results were available for 22 of these patients $(4.6 \%)$, and no C [lum $]_{\text {day } 7}$ results for were available for $24(5.0 \%)$. A further five patients with outlier val- 
Table I: Baseline characteristics of patients sampled for lumefantrine pharmacokinetics.

\begin{tabular}{|c|c|c|c|c|c|c|}
\hline \multirow[t]{2}{*}{ Variable } & \multicolumn{3}{|c|}{ Supervised arm } & \multicolumn{3}{|c|}{ Unsupervised arm } \\
\hline & $<5$ years & $5-14$ years & $\geq 15$ years & $<5$ years & $5-14$ years & $\geq 15$ years \\
\hline number sampled & 70 & 92 & 79 & 68 & 91 & 79 \\
\hline sex ratio (M/F) & $1.9(46 / 24)$ & $0.9(43 / 49)$ & $0.8(36 / 43)$ & I.I (36/32) & $0.7(37 / 54)$ & $0.5(28 / 5 \mathrm{I})$ \\
\hline median age (range) & $3(I-4)$ & $7(5-14)$ & $25(15-60)$ & $3(I-4)$ & $8(5-14)$ & $25(15-80)$ \\
\hline $\begin{array}{l}\text { parasite density } \\
\text { (median, IQR) }\end{array}$ & $\begin{array}{c}12344(4232-33 \\
799)\end{array}$ & $\begin{array}{c}15668(3750- \\
36523)\end{array}$ & $\begin{array}{c}6256(1957-15 \\
980)\end{array}$ & $\begin{array}{c}22777(11290-51 \\
775)\end{array}$ & $\begin{array}{c}\text { II } 367(3449-32 \\
475)\end{array}$ & $\begin{array}{c}6156(2749-19 \\
459)\end{array}$ \\
\hline $\begin{array}{l}\text { axillary } \\
\text { temperature }\left({ }^{\circ} \mathrm{C}\right) \\
\text { (mean, IQR) }\end{array}$ & $37.5(36.7-38.4)$ & $37.3(36.4-38.0)$ & $36.7(36.0-37.5)$ & $37.7(36.7-38.9)$ & $37.1(36.1-37.8)$ & $36.7(36 . I-37.2)$ \\
\hline $\begin{array}{l}\text { weight-adjusted } \\
\text { lumefantrine dose } \\
(\mathrm{mg} / \mathrm{Kg}) \text { (mean, } \\
\text { range) }\end{array}$ & $66(48-96)$ & $72(48-96)$ & $53(32-76)$ & $68(48-96)$ & $73(51-96)$ & $54(35-80)$ \\
\hline
\end{tabular}

ues were excluded from day 7 analyses. Characteristics of patients with missing data did not significantly differ from those of the analysable sample (data not shown).

Lumefantrine concentration distributions were skewed to the right. There was marked inter-individual variability in $\mathrm{C}[\mathrm{lum}]_{\mathrm{day} 3}$ and $\mathrm{C}[\mathrm{lum}]_{\mathrm{day} 7}$ for all age groups and arms (Figures 1 and 2). Using the fifth and $95^{\text {th }}$ centile concentrations, the variability in each age group $(<5,5-14, \geq 15$ y) was 13 200/857 (15.4-fold), 12 100/978 (12.4) and 10 $700 / 692(15.5)$ respectively for $\mathrm{C}[\mathrm{lum}]_{\mathrm{day} 3}$ and $718 / 58$ (12.4), 824/86 (9.6) and 870/101 (8.6) for C [lum] day 7 . Median supervised versus unsupervised $C[\mathrm{lum}]_{\text {day } 3}$ values (ng/mL) were 7040 vs. 2700 (<5 y), 5965 vs. 3310 (5-4 y), and 5320 vs. 3490 ( $\geq 15$ y) (p < 0.001 for all comparisons). Corresponding median C [lum $]_{\text {day } 7}$ values were 330

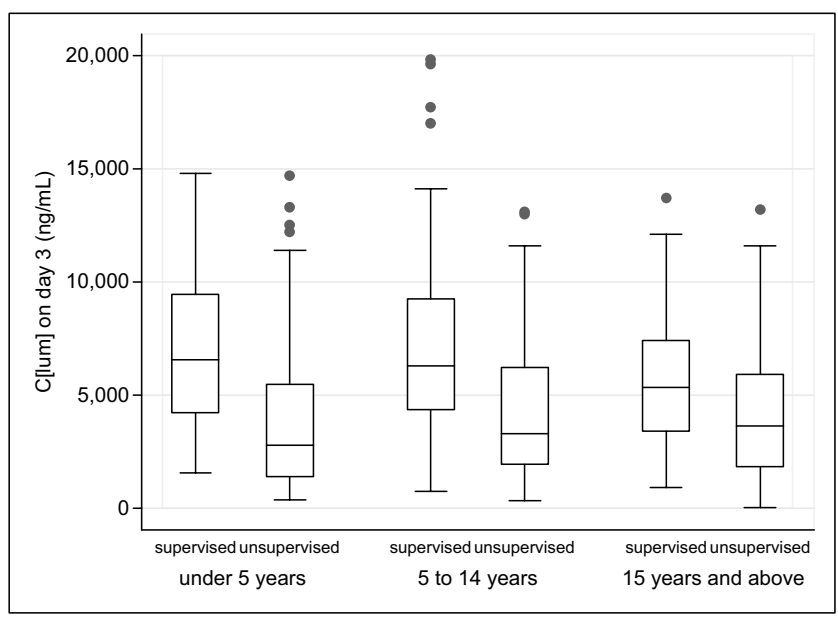

Figure I

Box plots of day 3 lumefantrine concentration by age group and arm. Each box displays the median, upper and lower quartiles of the respective distribution. Box whiskers represent the maximum and minimum range excluding any extreme outliers (shown as dots). vs. 156,402 vs. 249 , and 382 vs. 281 ( $p<0.001$ for all comparisons). C [lum $]_{\text {day } 3}$ and C [lum $]_{\text {day } 7}$ showed good correlation (Rho $=0.70, \mathrm{p}<0.001)$, with no differences across age groups or arms. 70/241 (29.0\%) supervised and 140/238 (58.8\%) unsupervised patients had a C [lum $]_{\text {day } 7}$ below $280 \mathrm{ng} / \mathrm{mL}$.

In multivariate linear models, unsupervised treatment had a strong negative association with $\mathrm{C}[\mathrm{lum}]_{\mathrm{day} 3}$ (Table 2 ). A history of vomiting was also a negative explanatory variable and a negative trend was apparent for decreasing weight-adjusted lumefantrine dose. Female gender was positively associated. No clear association of $\mathrm{C}[\mathrm{lum}]_{\text {day3 }}$ with age was noted. In the model for $\mathrm{C}[\mathrm{lum}]_{\text {day }}$ (Table $3)$, unsupervised treatment retained its strong negative effect. Age $<5 \mathrm{y}$ also had a strong negative association. A

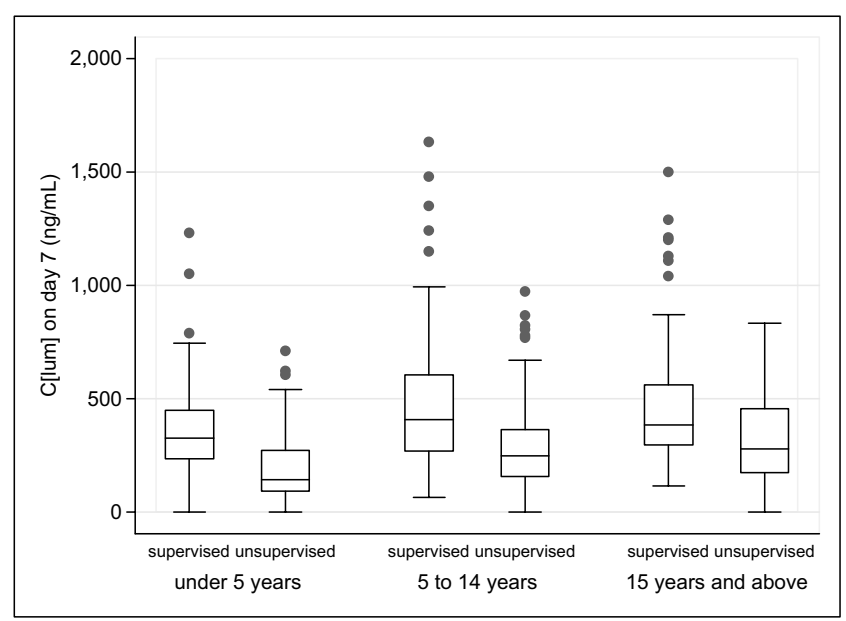

\section{Figure 2}

Box plots of day 7 lumefantrine concentrations by age group and arm. Each box displays the median, upper and lower quartiles of the respective distribution. Box whiskers represent the maximum and minimum range excluding any extreme outliers (shown as dots). 
and arm were found. Overall, however, both models accounted for only a small fraction of the observed variability in lumefantrine concentrations (adjusted $\mathrm{R}^{2}$ values $<0.25)$.

\section{Re-infection risk}

Of 957 patients enrolled in the trial, 946 were ITT-eligible and included in the Cox proportional hazards model. All patients were parasite negative by day 3 . By day 28 , there were 33 PCR-confirmed re-infections but no parasitological failures. Total person-time of follow up was 26,005 person-days, giving a re-infection rate of 0.00127 (33/ $26,005)$ person-days, or 0.46 per person-year. All re-infections occurred on or after day 21, and 22/34 (64.7\%) on day 28. After adjusting for age and arm, decreasing weightadjusted lumefantrine dose was associated significantly with a higher hazard of re-infection, although confidence intervals were wide (Table 4). In the subset of patients with an available $\mathrm{C}[\mathrm{lum}]_{\text {day } 7}$ result, the probability of reinfection increased significantly as $\mathrm{C}[\mathrm{lum}]_{\mathrm{day} 7}$ decreased, and no re-infections occurred in patients with levels $\geq 400$ $\mathrm{ng} / \mathrm{mL}$ (Table 5 ). We could not perform a multivariate regression, because $\mathrm{C}$ [lum $]_{\text {day } 7}$ lies in the causal pathway between the dependent (re-infection) and other explanatory variables. However, stratifying by age group, the only strong confounder detected by the Cox model, also showed a significant risk of re-infection with declining age (Table 5).

\section{Discussion}

This study has generated new and valuable information on the pharmacokinetics and dose-dependent effects of A/ $\mathrm{L}$ in malaria patients of all ages at a sub-Saharan African site experiencing stable transmission of multi-drug resistant $P$. falciparum, namely the kind of setting where highly efficacious ACTs like artemether-lumefantrine are needed and will probably be most beneficial.
In these Ugandan patients, we found that both $\mathrm{C}$ [lum $]_{\text {day } 3}$ and $C$ [lum $]_{\text {day } 7}$ displayed up to fifteen-fold inter-individual variability, consistent with other studies [13]. Median lumefantrine levels were significantly lower in unsupervised patients, but these differences did not affect cure rates at 28 days [8]. The $\mathrm{C}$ [lum $]_{\mathrm{day} 3}$ concentrations in the unsupervised patients were similar to those found in a previous adherence study in Mbarara [4].

C [lum $]_{\mathrm{day} 3}$ and C [lum $]_{\mathrm{day} 7}$ correlated well, but were affected differently by certain baseline patient variables. The peak lumefantrine concentration after the three day regimen occurs some 70 hours after intake of the first dose $[3,13]$. As a close surrogate, we sampled patients on day 3 , namely at approximately 72 hours. The C [lum $]_{\text {day } 3}$ may represent mostly drug intake, absorption from the small bowel and distribution: this could explain why unsupervised treatment, vomiting and a lower weight-adjusted lumefantrine dose were associated with a reduced $\mathrm{C}$ [lum $]_{\text {day } 3}$. By contrast, the $\mathrm{C}[\mathrm{lum}]_{\mathrm{day} 7}$ could be the result of drug metabolism and elimination (clearance), principally by the liver and biliary system: children under five had significantly lower $\mathrm{C}[\mathrm{lum}]_{\mathrm{day} 7}$, possibly because of enhanced metabolism and clearance. Interestingly, age was not a significant explanatory factor for the $\mathrm{C}[\mathrm{lum}]_{\text {day } 3}$ in this study, a contrasting finding with the $\mathrm{A} / \mathrm{L}$ adherence study [4]. The associations of female gender with $\mathrm{C}$ $[\mathrm{lum}]_{\mathrm{day} 3}$ and dizziness at baseline with $\mathrm{C}[\mathrm{lum}]_{\mathrm{day} 7}$ are harder to explain, and might be spurious results because of multiple significance tests. In Thai patients, age, weight, and gender were not associated with any of the main PK parameters but the trial did not include children of less than six years of age [3].

Despite highlighting these interesting associations, on the whole our models did not satisfactorily explain the variance in $\mathrm{C}$ [lum]. Previous studies have shown that the large effect on lumefantrine PK of lipid intake, which our

Table 4: Cox proportional hazards model of relative hazards of re-infection during 28 day follow-up (946 patients).

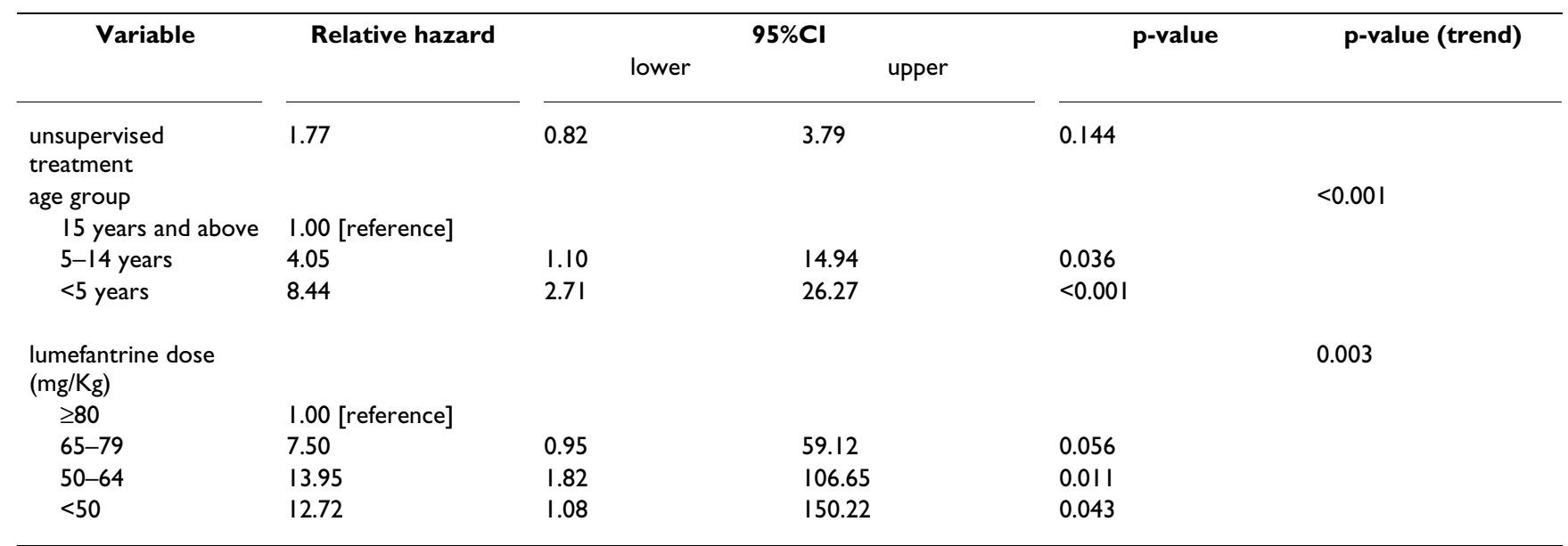


Table 5: Log-rank test of probability of survival (i.e. remaining re-infection free), by age group and day 7 lumefantrine concentration.

\begin{tabular}{|c|c|c|c|c|c|c|c|c|c|c|c|c|}
\hline \multirow{2}{*}{$\begin{array}{c}\text { C } \\
{\left[{ }_{7}(\mathrm{lum} / \mathrm{mL}]_{\text {day }}\right.}\end{array}$} & \multicolumn{3}{|c|}{$<5$ years } & \multicolumn{3}{|c|}{ 5-14 years } & \multicolumn{3}{|c|}{$\geq 15$ years } & \multicolumn{3}{|c|}{ Total } \\
\hline & $\mathrm{n}_{\mathrm{c}}$ & $n_{r}$ & $P_{\text {surv }}$ & $\mathrm{n}_{\mathrm{c}}$ & $n_{r}$ & $P_{\text {surv }}$ & $\mathrm{n}_{\mathrm{c}}$ & $\mathrm{n}_{\mathrm{r}}$ & $P_{\text {surv }}$ & $\mathrm{n}_{\mathrm{c}}$ & $\mathrm{n}_{\mathrm{r}}$ & $P_{\text {surv }}$ \\
\hline$<200$ & 47 & 5 & 0.889 & 32 & 4 & 0.871 & 33 & 2 & 0.938 & 112 & II & 0.898 \\
\hline 200-399 & 51 & 3 & 0.940 & 77 & 2 & 0.987 & 63 & 2 & 0.968 & 191 & 7 & 0.968 \\
\hline $400-599$ & 20 & 0 & 1.000 & 34 & 0 & 1.000 & 33 & 0 & 1.000 & 87 & 0 & 1.000 \\
\hline$\geq 600$ & 11 & 0 & 1.000 & 30 & 0 & 1.000 & 21 & 0 & 1.000 & 62 & 0 & 1.000 \\
\hline $\begin{array}{l}\text { p-value } \\
\text { (trend): }\end{array}$ & & 0.002 & & & 0.283 & & & 0.399 & & & $<0.001$ & \\
\hline
\end{tabular}

$n_{c}=$ number in category $n_{r}=$ number of re-infections $P_{\text {surv }}=$ probability of survival

study was not designed to measure, far outweighs other factors [13].

These findings should be generalized with caution. In Asia, Chinese patients had higher peak lumefantrine on day 3 than Thai patients treated with the same A/L regimen (four tablets over 48 hours) who in turn had higher values than European patients $[3,13]$. Median C [lum] day3 results in our study are broadly consistent with those of Thai patients but lower than those in Chinese patients, even though patients in this study received the six dose regimen. Apart from food intake, pharmacogenetic factors (e.g. the wide variability in CYP 3A, the cytochrome P450 enzyme responsible for artemether and lumefantrine metabolism [3,13]) and differences in nutritional status in African patients may be important and are avenues for further research.

In the multi-drug resistant areas of western Thailand, a day 7 lumefantrine concentration below $280 \mathrm{ng} / \mathrm{mL}$ was a reasonable predictor of treatment failure. In this study, there were no treatment failures despite day 7 lumefantrine concentrations $<280 \mathrm{ng} / \mathrm{ml}$ in $45 \%$ of all patients, a finding probably due to the high parasite sensitivity to lumefantrine in Uganda.

By contrast, a day 7 lumefantrine concentration of $<400$ $\mathrm{ng} / \mathrm{ml}$ and receiving a lower dose per $\mathrm{Kg}$ of lumefantrine were risk factors for re-infection during follow-up; this risk was thirteen-fold higher in patients receiving less than $65 \mathrm{mg} / \mathrm{Kg}$ compared to those receiving $\geq 80 \mathrm{mg} / \mathrm{Kg}$. Most re-infections became visible in the blood 21 to 28 days after start of treatment, when lumefantrine levels would be expected to be very low, and sub-therapeutic. In our study almost 50\% (134/286) of children under 5 years received less than $65 \mathrm{mg} / \mathrm{Kg}$ of lumefantrine; these children also experienced an additional age-related, eight-fold higher risk of re-infection compared to adults. Parasite reinfection has received far less attention than recrudes- cence. Nonetheless, in the era of highly efficacious ACTs like $\mathrm{A} / \mathrm{L}$, preventing re-infections may become an important public health issue, especially in children under five in stable high transmission areas and individuals during malaria epidemics; in both groups, re-infections cause high malaria morbidity and mortality. Our findings suggest that, in routine practice, low adherence and poor lipid intake could result in re-infection rates that would negate the benefits of high A/L efficacy.

This in vivo study extended to only 28 days. Had patients been monitored for 42 days, as recommended by some, we could have detected later recrudescences [14]. The sample of patients may not have been fully representative of a typical outpatient population because the trial had specific entry criteria, and the study environment may have modified patients' adherence patterns. The study was not designed to estimate pharmacokinetic parameters such as peak concentration and terminal half-life. Lumefantrine levels could only be measured on days 3 and 7 . Both of these time point measures are crude surrogates of the AUC, the key pharmacokinetic determinant of cure. Further modelling in different settings will be required to determine how useful these markers are.

Despite the limitations of this study, it is clear that a high day $28 \mathrm{~A} / \mathrm{L}$ cure rate can be achieved despite low plasma lumefantrine levels, even among unsupervised patients. This apparently favourable situation may, however, set up conditions for the selection of resistant parasites, especially in young children who not only harbour high biomass infections but also achieve the lowest day 7 lumefantrine levels. The prevention of de novo resistance to ACT combinations is clearly a crucial consideration that probably overrides the desirability of preventing novel infections through a post-treatment prophylactic effect [15]. In this regard, adherence to the six dose $\mathrm{A} / \mathrm{L}$ regimen, now recommended by WHO, will be critical. Other efficacious ACTs may also be unable to significantly prevent re- 
infections in high transmission areas, where the simultaneous deployment of an effective ACT and insecticideimpregnated bed nets is needed.

\section{Conclusion}

$\mathrm{A} / \mathrm{L}$ is a precious tool in the available arsenal against malaria morbidity and mortality, especially in African children. Although it needs to be made widely available to populations in need, care should also be taken to avoid creating favourable conditions for the emergence of lumefantrine-resistant malaria strains [16]. Further research is needed to explore the determinants of sub-optimal lumefantrine plasma levels and how to overcome these. Health systems deploying A/L should develop and strengthen strategies to maximize the effectiveness of the six-dose regimen, for which both high adherence and appropriate food intake are proven imperatives. Monitoring lumefantrine resistance should be an essential element of widespread implementation of this valuable drug combination. New studies should explore the synergistic effects of using ACTs and insecticide-impregnated bed nets.

\section{Authors' contributions}

FC, PP, CF, FB, WRJT and JPG designed the trial. FC and PP analysed data. CF, FB, SB, FG, ER, JB and IK were in charge of trial recruitment and on-site supervision, and contributed to data analysis. JKi, JKy and LF designed and supervised laboratory procedures, with the exception of pharmacokinetic assays, and interpreted PCR data. FC, PP, WRJ and JPG interpreted findings and wrote this paper with the contribution of other authors. All authors read and approved the final manuscript.

\section{Acknowledgements}

The study was funded by Médecins Sans Frontières. Novartis Pharma freely performed lumefantrine assays (we are grateful for this to Gilbert Lefèvre and Marie-Noëlle Bizot). Neither Médecins Sans Frontières nor Novartis Pharma contributed to protocol development, this analysis, or the writing of this paper. We wish to thank families participating in the trial, and additional members of the study team (Stephen Mugisha, Job Baguma, Ismael Sekimuli, Alex Muhumuza, Prossy Namiiro, Enid Nuwagaba, Joy Musabe, Winnie Lamulatu, Saidat Nabiyiki, Sulaiman Muwanga, Frederick Mutebi, Benon Tumwebaze, Bernice Anyango, Jeninah Atwebembeire, Tinka Kyoshabiire, David Agaba, Nathan Rutikarayo, Hassan Kivumbi, Faith Kabanda, and Grace Kyomugisha).

\section{References}

I. Wernsdorfer WH: Coartemether (artemether and lumefantrine): an oral antimalarial drug. Expert Rev Anti Infect Ther 2004, 2:181-196.

2. Ezzet F, Mull R, Karbwang J: Population pharmacokinetics and therapeutic response of CGP 56697 (artemether + benflumetol) in malaria patients. Br J Clin Pharmacol 1998, 46:553-561.

3. Ezzet F, van Vugt M, Nosten F, Looareesuwan S, White NJ: Pharmacokinetics and pharmacodynamics of lumefantrine (benflumetol) in acute falciparum malaria. Antimicrob Agents Chemother 2000, 44:697-704.
4. Fogg C, Bajunirwe F, Piola P, Biraro S, Checchi F, Kiguli J, Namiiro $P$, Musabe J, Kyomugisha A, Guthmann JP: Adherence to a six-dose regimen of artemether-lumefantrine for treatment of uncomplicated Plasmodium falciparum malaria in Uganda. Am J Trop Med Hyg 2004, 7 I:525-530.

5. Alilio MS, Kitua A, Njunwa K, Medina M, Ronn AM, Mhina J, Msuya F, Mahundi J, Depinay JM, Whyte S, Krasnik A, Bygbjerg IC: Malaria control at the district level in Africa: the case of the muheza district in northeastern Tanzania. Am J Trop Med Hyg 2004, 7I:205-2I3.

6. van Agtmael M, Bouchaud O, Malvy D, Delmont J, Danis M, Barette S, Gras C, Bernard J, Touze JE, Gathmann I, Mull R: The comparative efficacy and tolerability of CGP 56697 (artemether + lumefantrine) versus halofantrine in the treatment of uncomplicated falciparum malaria in travellers returning from the Tropics to The Netherlands and France. Int J Antimicrob Agents 1999, 12:159-169.

7. van Agtmael MA, Cheng-Qi S, Qing JX, Mull R, van Boxtel C): Multiple dose pharmacokinetics of artemether in Chinese patients with uncomplicated falciparum malaria. Int J Antimicrob Agents 1999, 12:151-158.

8. Piola P, Fogg C, Bajunirwe F, Biraro S, Grandesso F, Ruzagira E, Babigumira J, Kigozi I, Kiguli J, Kyomuhendo J, Ferradini L, Taylor W, Checchi F, Guthmann JP: Supervised versus unsupervised intake of six-dose artemether-lumefantrine for treatment of acute, uncomplicated Plasmodium falciparum malaria in Mbarara, Uganda: a randomised trial. Lancet 2005, 365:1467-1473.

9. Legros D, Johnson K, Houpikian P, Makanga M, Kabakyenga JK, Talisuna AO, Taylor WR: Clinical efficacy of chloroquine or sulfadoxine-pyrimethamine in children under five from southwestern Uganda ith uncomplicated falciparum malaria. Trans $R$ Soc Trop Med Hyg 2002, 96:199-20I.

10. Priotto G, Kabakyenga J, Pinoges L, Ruiz A, Eriksson T, Coussement F, Ngambe T, Taylor WR, Perea W, Guthmann JP, Olliaro P, Legros $D$ : Artesunate and sulfadoxine-pyrimethamine combinations for the treatment of uncomplicated Plasmodium falciparum malaria in Uganda: a randomized, double-blind, placebocontrolled trial. Trans $R$ Soc Trop Med Hyg 2003, 97:325-330.

II. Snounou G: Genotyping of Plasmodium spp. Nested PCR. Methods Mol Med 2002, 72:103-116.

12. Mansor SM, Navaratnam V, Yahaya N, Nair NK, Wernsdorfer WH, Degen PH: Determination of a new antimalarial drug, benflumetol, in blood plasma by high-performance liquid chromatography. J Chromatogr B Biomed Appl 1996, 682:32I-325.

13. White NJ, van Vugt M, Ezzet F: Clinical pharmacokinetics and pharmacodynamics and pharmacodynamics of artemetherlumefantrine. Clin Pharmacokinet 1999, 37: 105- 125.

14. Stepniewska K, Taylor WR, Mayxay M, Price R, Smithuis F, Guthmann JP, Barnes K, Myint HY, Adjuik M, Olliaro P, Pukrittayakamee S, Looareesuwan S, Hien TT, Farrar J, Nosten F, Day NP, White NJ: In vivo assessment of drug efficacy against Plasmodium falciparum malaria: duration of follow-up. Antimicrob Agents Chemother 2004, 48:427I-4280.

15. White NJ, Pongtavornpinyo W: The de novo selection of drugresistant malaria parasites. Proc Biol Sci 2003, 270:545-554.

16. Sisowath C, Stromberg J, Martensson A, Msellem M, Obondo C Bjorkman A, Gil JP: In vivo selection of Plasmodium falciparum pfmdrl $86 \mathrm{~N}$ coding alleles by artemether-lumefantrine (Coartem). J Infect Dis 2005, 191:1014-1017. 